\title{
A comparative study between repeated failures and successful trials after Intra-cytoplasmic Sperm Injection
}

\author{
Hanan Mohamed Gabr Youssef ${ }^{*}$, Nehal Ali Abu-Elnaga ${ }^{2}$, Amira Badereldin Mehaney Abdel Ghany ${ }^{3}$, Serag Eldin Mansour Mahmoud ${ }^{4}$ and \\ Amira Salim Abd El-Khalek Salim ${ }^{1}$ \\ ${ }^{1}$ Unit of Obstetrics and Gynecology, Health Radiation Research Department, National Center for Radiation Research and Technology. Egyptian Atomic Energy Authority, \\ Egypt \\ ${ }^{2}$ Department of Embryology, Zoology Department, Faculty of Science, Al-Azhar University, Egypt \\ ${ }^{3}$ Department of Embryology, International Islamic Center for Population Studies and Research, Al-Azhar University, Egypt \\ ${ }^{4}$ Department of Obstetrics and Gynecology, International Islamic Center for Population Studies and Research, Assisted reproductive unit, Al-Azhar University, Egypt
}

\begin{abstract}
Background: Repeated failures are determined when embryos fail to implant following several intra-cytoplasmic sperm injection (ICSI) trials, either due to maternal or embryonic causes. Failure of implantation due to embryonic causes is due to either genetic abnormalities or other factors that impair its ability to develop and implant normally.
\end{abstract}

Aim: Our objective is to study and evaluate the impact of oocytes dysmorphology on repeated failures; we evaluate the MII oocytes morphologies, fertilization rates, embryo qualities in repeated failures and in successful cycles after ICSI.

Design: Prospective case-control study.

Settings: The International Islamic Center for Population Studies and Research, Assisted Reproductive Unit, Al-Azhar University.

Patients and methods: 180 patients undergoing ovarian hyperstimulation for ICSI.

1-Group (1): 60 women as control group all have successful ICSI first trial.

2-Group (2): 60 women have successful third ICSI trial after two failures.

3-Group (3): 60 women have repeated failure of the third or fourth ICSI trials.

MII Oocytes are evaluated to detect all morphological abnormalities.

Results: The oocytes morphological abnormalities are significantly higher in the repeated failure group (3) than in the second group (2), which has higher abnormalities than the first group (1). Presence of multiple oocytes abnormalities is associated with a significant decrease in the fertilization rate, embryo quality and pregnancy.

Conclusions: Repeated failures in ICSI cycles can be due to MII oocytes multiple morphological abnormalities due to their negative impact on fertilization, embryo quality which prevent pregnancy.

\section{Synopsis}

Repeated failures in ICSI cycles are due to many causes either in mother or in oocytes and embryos, this study will focus on the oocytes and embryos as important causes of repeated failures in young women with no anatomical or immunological causes underling RF.

\section{Introduction}

Repeated implantation failure (RF) is defined as failure of implantation in at least three consecutive assisted reproduction trials, in each cycle one to two embryos of high quality were transferred [1]. This failure applies repeated distress on the couples and requires increases in the money spent for repeating the procedure and the investigations. For implantation to occur two main components are needed; a healthy embryo and a good receptive endometrium. Many mediators involved in implantation are coming from the embryo, from the endometrium, and with adaptation of the maternal immune system [2-4].
Maternal causes of RF are anatomical malformations of uterus, fibroids, intrauterine adhesions and hydrosalpinx which interfere with normal implantation [5]. A functioning and receptive endometrium is crucial for embryo implantation. During the menstrual cycle the endometrium undergoes both morphologic and biologic changes that prepare it for the interaction with the embryo and for the implantation. There is an association between RF and thrombophilia which disturb

${ }^{\star}$ Correspondence to: Hanan Mohamed Gabr Youssef, Unit of Obstetrics and Gynecology, Health Radiation Research Department, National Center for Radiation Research and Technology. Egyptian Atomic Energy Authority, Egypt, Tel: 01009706470; E-mail: hanangabr62@gmail.com

Key words: ICSI, repeated failure, successful trials, oocytes

Received: October 26, 2019; Accepted: November 14, 2019; Published: November 18, 2019 
blood flow to the endometrium, placenta and hinder the endometrial receptivity [6].

The immunologic system has a major role in implantation and maintenance of pregnancy [7]. Couples who share common HLA alleles may suffer from RF, due to hampering the immunoregulatory function associated with maternal tolerance to the embryo [8]. As inadequate uterine receptivity is responsible for approximately twothirds of implantation failures, the embryo itself is responsible for only one-third of these failures [1]. Increased incidence of chromosomal translocations, mosaics, inversions and deletions of genetic material were reported in patients with repeated failures after ICSI [9]. In another study, twice the chromosomal abnormalities were detected in embryos from the repeated failures patients compared to embryos of the controls [10]; even embryos that are morphologically of good quality may stop to develop inside the uterus and fail to progress to a blastocyst stage.

Poor fertilization rate has been reported due to oocytes dysmorphology [11], or if the consistency of the zona pellucida is abnormal [12]. Researchers linked the morphological variations of oocytes to extrinsic factors such as stimulation protocols [13,14]. They identify the underlying molecular mechanisms by which different stimulation protocols influence oocytes and embryos quality [15]. Until now, the fate of dysmorphic oocytes, the fertilization rate, embryo quality and pregnancy outcome from dysmorphic oocytes are unknown [16]. Our aim is to clarify the influence of the oocyte's morphological abnormalities on the repeated ICSI failure cycles in comparison with the successful cycles.

\section{Patients and methods}

This observational case control study was done from January until December 2018, on 180 women undergoing ICSI, divided into three groups and patients were recruited from the International Islamic Center for Population Studies and Research, assisted reproductive unit, Al-Azhar University. This research study was in accordance with the ethical standards of the assisted reproductive unit, and was approved by the ethical committee of the NCRRT, and the study was conducted in accordance with the Helsinki Declaration and all participants gave informed consent before their inclusion in this study. All patients had controlled ovarian hyperstimulation with the long protocol and had been referred to ICSI unit; were screened for selecting the patients eligible for inclusion. The subjects recruited were classified into 3 groups:

1-Group 1 (Control group): includes 60 patients selected to be (age matched, normal ovarian response, and with first ICSI trial and all ended with pregnancy.

2-Group 2: consists from 60 patients were selected from patients had 2 failed pregnancy after ICSI trials before this successful third trial with positive pregnancy.

3-Group 3: consists from 60 women selected with 3 failed ICSI trials, all women failed to have pregnancy for this third or fourth trials.

The inclusion criteria for patients were middle ages between 25 to 38 years, and the body mass index $(\mathrm{BMI})<35 \mathrm{~kg} / \mathrm{m}^{2}$, females factor of infertility with normal good quality of sperms of their husbands, regular menses, presence of both ovaries, and normal uterine cavity, and fair ovulation response to induction. And the exclusion criteria were patients with basal follicle-stimulating hormone (FSH) $\geq 10 \mathrm{IU} /$ $\mathrm{mL}$, history of poor or high ovarian response to gonadotrophin administration in previous cycle, polycystic ovarian syndrome, moderate and severe endometriosis, history of previous surgery on ovaries, history of hormonal therapy in the last 3 months (poor responders diagnosed as having less than four dominant follicles on the day of hCG administration and or less than four oocytes retrieved, a peak $\mathrm{E}_{2}$ level of $<500 \mathrm{pg} / \mathrm{ml}$ and lastly the male factor of infertility.

Medical history had been taken from each patient with the diagnosis, duration of infertility, number of previous pregnancies, associated diseases with their therapy, initial examination of semen analysis of the husband, transvaginal ultrasound, and hysterosalpingogram or sonohysterogram, or hysteroscopic report were done for all patients to exclude uterine anatomical and endometrial factors which hinder the implantation of embryos.

Assay of FSH, LH, PRL, TSH and E2, the liver function tests (AST, ALT, total protein, albumin, both total and direct bilirubin), kidney function tests (Urea, Creatinine), random glucose level, and analysis of hemoglobin level, hematocrit, RBC, WBC and Platelets count. All subjects received the GnRH long protocol. The GnRH long protocol consisted of a depot injection of therapeutic dose triptorelin (Decapeptyl $3.75 \mathrm{mg}$ ) on day 21 of the preceding cycle, after 14 days the down-regulation status was assessed. Patients were considered responding when endometrial thickness reached $7 \mathrm{~mm}$ or serum E2 was $<50 \mathrm{pg} / \mathrm{ml}$, progesterone level was $<0.5 \mathrm{ng} / \mathrm{ml}$. Following downregulation confirmation, gonadotrophin was administered in dose $75-300 \mathrm{IU} / \mathrm{ml} /$ day.

Follow-up of induction and ovarian response by vaginal ultrasound and ovulation was triggered by administration of hCG (10,000 IU) I.M. when at least 4 follicles reached $18 \mathrm{~mm}$ in diameter. After 36 hours oocytes were retrieved and examined with stereo microscope. Oocytes were denudated from cumulus oophorous by exposure to 80 $\mathrm{IU} / \mathrm{ml}$ hyaluronidase enzyme in HEPES-buffered medium, followed by mechanical removal of the corona radiata. Oocytes were assessed for their maturation and morphology under an inverted microscope by one embryologist. Good-quality mature human oocytes have a clear, moderately granular, homogeneous cytoplasm that does not contain inclusions, a small perivitelline space (PVS), a round clear, colorless zona pellucida (ZP) and single unfragmented polar body (PB) $[11,17]$. Dysmorphic oocytes are commonly classified as having abnormal cytoplasm (dark cytoplasm, not homogenous or increased cytoplasmic granularity), cytoplasmic inclusions (vacuoles, refractile bodies), an abnormal oocyte shape (oval), an abnormal ZP, an abnormal PVS, and an abnormal PB (fragmented or irregular PB) [11,17]. Metaphase II oocytes were separated from the immature oocytes (metaphase I oocytes and germinal vesicle) just before sperm injection (3-4 h after retrieval). Injected oocytes were examined for integrity and fertilization about 16-18 hours after ICSI. Oocytes were considered normally fertilized when evaluating the presence of two pronuclei (2 PN) and the extrusion of the second PB. The fertilization rate after ICSI was usually expressed per number of injected oocytes. After 48 hours, embryos that had cleaved to the two or four cell-stage scored according to equality of blastomeric size and proportion of nucleate fragments.

Then 2-3 good quality embryos for each patient were transferred to the uterus. Patients performed a serum beta HCG for detection of pregnancy.

\section{Results}

Table 1 clarified that the cause of infertility in the group 3 of RF was due to ovulation problems, and in group 2 due to ovulation and unexplained infertility; meanwhile the cause of infertility in the control group was due to tubal and unexplained infertility factors. 
FSH ampoules needed for controlled ovarian hyperstimulation is significantly the highest in group 3 , with estrogen peak is the lowest in group 3; day of oocytes pickup is significantly higher in group 3 than group 2 and control group. It is clear that infertility duration and ICSI trials are more in repeated failures group 3 than the other two groups (Table 2).

There are significant differences in oocyte morphological abnormalities between the three groups using One-way ANOVA test. Positive pregnancy in group 1, in group 2 after 2 failures and negative pregnancy in group 3. Multiple abnormalities in the oocytes yields low quality embryos with no pregnancy in the repeated failure group 3 (Table 3).

Table 4 clarifies that PB, ZP, PVS, oocyte shape, cytoplasm, oolema, corona radiata, and vacuoles abnormalities are all inversely significantly correlated with fertilization rate and high-quality embryos, and positively significantly correlated with low quality embryos.

\section{Statistical analysis}

All Analyses were done using SPSS version 20. Quantitative variables were described as means \pm SD and by summation and percentages. Comparison between groups was performed by One-wayANOVA. Nominal and frequency data were analyzed using Chi-square test. $P$ values less than 0.05 were considered statistically significant for all statistical tests.

\section{Discussion}

Orvieto suggested the definition of repeated failure is established after three failed in vitro fertilization-embryo transfer (IVF-ET) cycles with good quality embryos transferred [18]. In this study the comparison of oocytes, fertilization, embryos quality, and pregnancy between the three groups revealed the negative influence of oocytes dysmorphology on ICSI outcome. There is significant positive correlation between the age of patients and all oocytes abnormalities except corona radiata, ZP and PVS. Also, age is significantly inversely correlated with fertilization and high-quality embryos. Duration of infertility is significantly positively correlated with all oocytes abnormalities and significantly inversely correlated with fertilization and high-quality embryos. There are significant positive correlations between the number of HMG ampoules given to the patients and all oocytes abnormalities except ZP and PVS, and significant inverse correlation between HMG ampoules with fertilization rate and high-quality embryos. A previous study found a relation between the number of gonadotrophin ampoule injections and presence of large PVS [19].

In our study, in group 3 there are multiple MII oocyte abnormalities which reach (405) abnormalities in the (98) MII oocytes which result in about (4.13) abnormalities in each MII oocyte with the formation of low quality embryos (100\%), about (1.58) low quality embryos for each patient were developed in this group with result of negative pregnancy outcome.

Table 1. Comparison between the studied groups as regarding the cause of infertility

\begin{tabular}{|c|c|c|c|}
\hline Cause of infertility & Control group (Group 1) & $\begin{array}{c}\text { Positive pregnancy in 3-trial } \\
\text { (Group 2) }\end{array}$ & 0 \\
\hline Tubal factor & $40 / 60$ & $52 / 60$ \\
\hline Ovulation factor & 0 & 0 & 0 \\
\hline Uterine factor & - & 0 & $50 / 60$ \\
\hline Endometriosis & 0 & 0 \\
\hline Unexplained infertility & $20 / 60$ & 0 \\
\hline Mixed case & 0 & 0 \\
\hline
\end{tabular}

Table 2. Comparison between the Studied Groups as regarding the patients' characteristics, hormonal and blood analysis using oneway-ANOVA

\begin{tabular}{|c|c|c|c|c|c|}
\hline Parameter & Control group Group 1 & $\begin{array}{c}\text { Positive pregnancy after RF } \\
\text { Group } 2\end{array}$ & $\begin{array}{c}\text { Negative pregnancy RF } \\
\text { Group } 3\end{array}$ & $\mathbf{F}$ & Significance \\
\hline Age & $28.65 \pm 3.16$ & $30.1 \pm 2.4$ & $32.65 \pm 3.3$ & 27.27 & $0.000^{*}$ \\
\hline BMI & $28.87 \pm 2.8$ & $27.08 \pm 1.88$ & $27.24 \pm 1.85$ & 11.88 & $0.000^{*}$ \\
\hline Infertility duration & $4.11 \pm 1.2$ & $4.26 \pm 1.19$ & $8.14 \pm 1.48$ & 189.1 & $0.000^{*}$ \\
\hline FSH & $6.0 \pm 0.59$ & $6.02 \pm 0.56$ & $5.35 \pm 1.1$ & 15 & $0.00^{*}$ \\
\hline LH & $4.03 \pm 1.3$ & $4.06 \pm 1.28$ & $4.04 \pm 1.56$ & 0.006 & 0.994 \\
\hline Prolactin & $18.465 \pm 4.7$ & $17.04 \pm 4.1$ & $16.17 \pm 4.3$ & 4.89 & $0.009^{*}$ \\
\hline E2 & $42.8 \pm 2.71$ & $45.1 \pm 3.5$ & $43.56 \pm 3.2$ & 8.23 & $0.000^{*}$ \\
\hline FSH amp. & $3.65 \pm 1.05$ & $3.37 \pm 0.551$ & $5.3 \pm 0.696$ & 103.19 & $0.000^{*}$ \\
\hline Day of pickup & $12.42 \pm 0.72$ & $12.00 \pm 1.16$ & $13.52 \pm 2.43$ & 14.18 & $0.000^{*}$ \\
\hline Estrogen peak & $2530.82 \pm 333.4$ & $2480.2 \pm 296.74$ & $2345.0 \pm 582.49$ & 3.08 & $0.048^{*}$ \\
\hline TSH & $2.20 \pm 0.65$ & $2.58 \pm 0.78$ & $2.08 \pm 0.84$ & 6.29 & $0.002^{*}$ \\
\hline Hemoglobin & $12.7 \pm 0.45$ & $12.46 \pm 0.42$ & $12.45 \pm 0.6$ & 0.44 & 0.645 \\
\hline RBCs & $4.38 \pm 1.04$ & $4.32 \pm 0.2$ & $4.43 \pm 0.3$ & 0.693 & 0.501 \\
\hline WBCs & $6.78 \pm 1.76$ & $7.02 \pm 1.43$ & $6.66 \pm 1.8$ & 0.459 & 0.459 \\
\hline PLTs & $310.6 \pm 50.8$ & $318.1 \pm 56.2$ & $319.9 \pm 61.2$ & 6.5 & $0.00^{*}$ \\
\hline Random B. glucose & $90.8 \pm 11.7$ & $94.0 \pm 10.7$ & $94.1 \pm 12.1$ & 1.96 & 0.143 \\
\hline urea & $22.7 \pm 2.9$ & $20.4 \pm 3.5$ & $23.63 \pm 3.1$ & 16.15 & $0.000^{*}$ \\
\hline Creatinine & $0.84 \pm 0.08$ & $0.84 \pm 0.85$ & $0.84 \pm 0.1$ & 0.037 & 0.963 \\
\hline ALT & $15.48 \pm 4.86$ & $14.5 \pm 3.5$ & $14.8 \pm 5.15$ & 0.721 & 0.488 \\
\hline AST & $17.71 \pm 4.46$ & $16.7 \pm 3.8$ & $17.55 \pm 6.23$ & 0.714 & 0.491 \\
\hline Albumin & $4.45 \pm 0.182$ & $4.47 \pm 0.21$ & $4.47 \pm 0.19$ & 0.966 & 0.383 \\
\hline Number of ICSI trials & $1.0 \pm 0.000$ & $2.0 \pm 0.21$ & $3.37 \pm 0.505$ & 688.57 & $0.000^{*}$ \\
\hline
\end{tabular}


Youssef HMG (2019) A comparative study between repeated failures and successful trials after Intra-cytoplasmic Sperm Injection

Table 3. Comparison between the 3 groups, Group 1 Control (+ve pregnancy), Group 2 (+ve pregnancy) after 2-Failures, and Group 3 (-ve pregnancy) after 3-RF in ICSI

\begin{tabular}{|c|c|c|c|c|}
\hline Groups & G1-Control Positive pregnancy & $\begin{array}{c}\text { G2- } 2 \text { RF } \\
\text { Positive pregnancy }\end{array}$ & G3-3 RF -Negative pregnancy & Significance \\
\hline Number of patients & $\mathrm{N}=60$ & $\mathrm{~N}=60$ & $\mathrm{~N}=60$ & \\
\hline $\begin{array}{l}\text { Total no. of oocytes on U/S } \\
\text { (expected oocytes) }\end{array}$ & $480(8.0)$ & $452(7.53)$ & $447(7.45)$ & 0.3 \\
\hline Oocytes Retrieved & $412(85.8)$ & $350(77.4)$ & $226(50.5)$ & $0.000^{*}$ \\
\hline $\begin{array}{l}\text { Number of MII oocytes } \\
\text { (\% from oocytes retrieved) } \\
\text { N of MII/ patient }\end{array}$ & $\begin{array}{c}329(80) \\
5.37\end{array}$ & $\begin{array}{c}244(69.7) \\
4.07\end{array}$ & $98(43.3) 1.63$ & $0.000^{*}$ \\
\hline $\begin{array}{l}\text { Number of MI oocytes } \\
\text { (\% from oocytes retrieved) }\end{array}$ & $71(17.2)$ & $76(21.7)$ & $75(33.1)$ & 0.213 \\
\hline $\begin{array}{l}\text { Germinal vesicles } \\
\text { (\% from oocytes retrieved) }\end{array}$ & $10(2.4)$ & $10(2.8)$ & $17(7.5)$ & 0.991 \\
\hline $\begin{array}{l}\text { Number of empty oocytes } \\
\text { (\% from oocytes retrieved) }\end{array}$ & $2(0.4)$ & $20(5.7)$ & $36(15.9)$ & $0.000^{*}$ \\
\hline $\begin{array}{l}\text { Corona radiata } \\
\text { (\% per MII oocytes) }\end{array}$ & $5 / 329(1.5)$ & 0 & 24/98 (24.4) & $0.000^{*}$ \\
\hline $\begin{array}{l}\text { Zona Pellucida } \\
\text { (\% per MII oocytes) }\end{array}$ & $25 / 329(7.5)$ & $120 / 244(49.2)$ & $55 / 98(56.1)$ & $0.000^{*}$ \\
\hline $\begin{array}{l}\text { Polar Body } \\
\text { (\% per MII oocytes) }\end{array}$ & $18 / 329(5.5)$ & $14 / 244(5.7)$ & 47/98 (47.9) & $0.000^{*}$ \\
\hline $\begin{array}{l}\text { Perivitelline space } \\
\text { (\% per MII oocytes) }\end{array}$ & $24 / 329(7.3)$ & $66 / 244(27)$ & $77 / 98(78.5)$ & $0.000^{*}$ \\
\hline $\begin{array}{l}\text { Cytoplasm abnormality } \\
\text { (\% per MII oocytes) }\end{array}$ & $5 / 329(1.5)$ & $24 / 244(9.8)$ & $81 / 98(82.6)$ & $0.000^{*}$ \\
\hline $\begin{array}{l}\text { Vacuoles } \\
\text { (\% per MII oocytes) }\end{array}$ & 0 & 0 & $40 / 98(40.8)$ & $0.000^{*}$ \\
\hline $\begin{array}{l}\text { Oolema abnormality } \\
\text { (\% per MII oocytes) }\end{array}$ & 0 & 0 & $40 / 98(40.8)$ & $0.000^{*}$ \\
\hline $\begin{array}{l}\text { Shape abnormality } \\
\text { (\% per MII oocytes) }\end{array}$ & 0 & $8 / 244(3.2)$ & $41 / 98(41.8)$ & $0.000^{*}$ \\
\hline $\begin{array}{l}\text { Fertilization rate } \\
(\% \text { MII oocytes) }\end{array}$ & $329 / 329(100)$ & $240 / 244(98.3)$ & 95/98 (96.9) & $0.000^{*}$ \\
\hline $\begin{array}{l}\text { Cleavage rate at day } 3 \\
\text { (\% Fertilization) }\end{array}$ & $329 / 329(100)$ & $240 / 240(100)$ & 95/95 (100) & $0.000^{*}$ \\
\hline $\begin{array}{l}\text { High quality embryo } \\
(\% \text { Fertilization })\end{array}$ & $319 / 329(97)$ & $210 / 240(87.5)$ & 0 & $0.000^{*}$ \\
\hline $\begin{array}{l}\text { Low quality embryo } \\
\text { (\% Fertilization) }\end{array}$ & $10 / 329(3)$ & $30 / 240(12.5)$ & 95/95 (100) & $0.000^{*}$ \\
\hline Pregnancy test & Positive pregnancy & Positive pregnancy After 2 failures & Negative pregnancy & $0.000^{*}$ \\
\hline
\end{tabular}

Table 4. Correlation between abnormalities in oocytes, with high quality embryos, low quality embryos and fertilization

\begin{tabular}{|c|c|c|c|}
\hline Pearson correlation of & Fertilization rate & High quality Embryo & Low quality Embryo \\
\hline $\begin{array}{l}\text { Polar Body } \\
\text { p-value }\end{array}$ & $\begin{array}{c}-0.255-^{* *} \\
0.001\end{array}$ & $\begin{array}{c}-0.256-{ }^{* *} \\
0.001\end{array}$ & $\begin{array}{c}0.193^{* * *} \\
0.01\end{array}$ \\
\hline $\begin{array}{l}\text { Zona pellucida } \\
\text { p-value }\end{array}$ & $\begin{array}{c}-0.239-^{* *} \\
0.001\end{array}$ & $\begin{array}{l}-0.203-^{* *} \\
0.006\end{array}$ & $\begin{array}{l}0.078 \\
0.296\end{array}$ \\
\hline $\begin{array}{l}\text { Perivitelline space } \\
\text { p-value }\end{array}$ & $\begin{array}{l}-0.295-* * \\
0\end{array}$ & $\begin{array}{l}-0.299-* * \\
0\end{array}$ & $\begin{array}{l}0.238^{* *} \\
0\end{array}$ \\
\hline $\begin{array}{l}\text { Oocyte Shape } \\
\text { p-value }\end{array}$ & $\begin{array}{c}-0.391-{ }^{* *} \\
0\end{array}$ & $\begin{array}{c}-0.357-{ }^{* *} \\
0\end{array}$ & $\begin{array}{l}0.204^{* * *} \\
0\end{array}$ \\
\hline $\begin{array}{c}\text { Cytoplasm abnormality } \\
\text { p-value }\end{array}$ & $\begin{array}{c}-0.649-{ }^{* *} \\
0\end{array}$ & $\begin{array}{c}-0.645-^{* *} \\
0\end{array}$ & $\begin{array}{c}0.490^{* * *} \\
0\end{array}$ \\
\hline $\begin{array}{l}\text { Oolema } \\
\text { p-value }\end{array}$ & $\begin{array}{c}-0.365-^{* *} \\
0\end{array}$ & $\begin{array}{c}-0.368-^{* *} \\
0\end{array}$ & $\begin{array}{l}0.298^{* * *} \\
0\end{array}$ \\
\hline $\begin{array}{l}\text { Corona radiata } \\
\text { p-value }\end{array}$ & $\begin{array}{l}-0.465-^{* *} \\
0\end{array}$ & $\begin{array}{l}-0.452-* * \\
0\end{array}$ & $\begin{array}{l}0.326^{* *} \\
0\end{array}$ \\
\hline $\begin{array}{l}\text { Vacuoles } \\
\text { p-value }\end{array}$ & $\begin{array}{c}-0.441-^{* *} \\
0\end{array}$ & $\begin{array}{c}-0.424--^{* *} \\
0\end{array}$ & $\begin{array}{l}0.296^{* *} \\
0\end{array}$ \\
\hline $\begin{array}{l}\text { Fertilization rate } \\
\text { p-value }\end{array}$ & 1 & $\begin{array}{l}0.970^{* *} \\
0\end{array}$ & $\begin{array}{c}-0.698-^{* *} \\
0\end{array}$ \\
\hline
\end{tabular}


In group 2 there are about (232) abnormalities in the (244) oocytes which constitutes 0.95 abnormalities in each MII and seems that ZP and PVS abnormalities don't hinder the formation of high-quality embryos which are formed by a ratio of $(210 / 240)$ with percentage of $(87.5 \%)$. In this group there are about (3.5) embryos from the high quality and 0.5 of the low quality which give the possibility to transfer $2-3$ high quality embryos for the patient, and all patients in this group give + ve pregnancy.

In group 1 there are very few abnormalities and most of them are ZP and PVS (7.5\%) for each abnormality, which seem not to affect the formation of high quality embryos (5.3) high quality embryos for each patient and all the patients in this group have +ve pregnancy.

There is significant decrease in number of oocytes retrieved from the group 3 with significant decrease in MII oocytes, and significant increase in empty oocytes compared to group 2 and group 1 . There are significant increases in all MII oocytes abnormalities in group 3 than in the group 2 and group 1 . It seems that the high cytoplasmic abnormalities affect the fertilization rate, the embryos quality and lastly pregnancy rate. Moreover, the very high significant increases in oolema, shape and vacuoles abnormalities in group 3 than in the other groups hinder the presence of good quality embryos and consequently prevent the occurrence of pregnancy. There are no vacuoles or oolema abnormality in both groups 1 and 2, and shape abnormality is in very small percentage in group 2 .

In group 3 there are significant increases in PVS abnormality (78.5\%), in ZP abnormality (56.1\%), in PB abnormality reach (47.9\%), and in corona radiata abnormality $(24.4 \%)$, which are all significantly different than groups 2 and 1.

Consistent with our study, in several studies, researchers reported that the cytoplasmic abnormalities and vacuoles had negative influences on fertilization rates, embryo quality and pregnancy [20-24].

However, our finding also demonstrated positive impact of the presence of vacuoles, oolema, cytoplasm, PVS abnormalities and multiple oocyte abnormalities on fertilization rate, embryo quality and pregnancy outcome. Consistent with our study, a recent meta-analysis demonstrated that the probability of fertilization is significantly decreased by the presence of large PB, large PVS, or vacuoles, and the cytoplasmic vacuoles may be associated with severe oocyte degeneration [17].

Ashrafi, et al. observed no impact of large PVS on fertilization rate and embryo quality and reported that this type of variation in the oocyte morphology has no negative biological consequence [20].

Other researchers found no relationship between oocyte dysmorphology and ICSI and concluded that oocyte morphology and meiotic spindle presence or absence can only predict fertilization, cleavage rates and embryo quality, but do not help in daily ICSI practice for choosing the metaphase II oocyte that will lead to good embryo and pregnancy [25]. But in our study, the fertilization potential of dysmorphic MII oocytes, with their subsequent embryonic development and embryo quality are all hindered.

In consistent to our findings, Shi et al. found that dark ZP had a negative effect on the clinical outcome of IVF/ICSI cycles and could be considered as a potential selective marker for embryologists during daily laboratory work [26]. Oocytes with cytoplasmic inclusions [27], vacuoles [24,27], refractile bodies [24], dark ZP [24], a large PVS [24,27], and abnormal PB [24] all have negative effect on ICSI outcome.
In contrast with our findings, researchers reported that the dysmorphic oocytes had minor impacts on fertilization rate, pronuclear morphology and embryo quality in women with normal ovarian response [27], a relatively good fertilization rate was also reported in oocytes exhibiting cytoplasmic inclusions [28], refractile bodies [27], a dark ZP [27,29], debris in the PVS [29], a large PVS [30], and an abnormal PB [31]. Poor clinical outcomes were observed with transfer of embryos derived from dysmorphic oocytes without causing gestation or newborn problems [32].

Researchers recently identify constitutive defects in the endometrium underlying repeated implantation failure presented as a specific transcriptomic signature which might predict RF [33]. Others focus on the embryo, and particularly the impact of aneuploidy [34]. An earlier study found that there was a significantly higher rate of chromosomal anomalies, specifically aneuploidies among those with repeated implantation failure, and when genetic screening of the embryos using FISH were done with selection of normal embryos for transfer, the implantation rate was $(24.6 \%)$, comparable with young fertile controls, $(24.1 \%)$. Women $>37$ years old had the highest rates of chromosomal abnormalities in chromosome 21 and 22, and those $<37$ years old had higher rates of abnormalities in chromosome 13 [10].

Researchers recommended that women with RF should be karyotyped to determine chromosomal balanced translocations which can lead to aneuploidy in their oocytes [1].

Novel embryo assessment and selection procedures, by time-lapse imaging and metabolomics, might give better evaluation of embryo quality and viability with highest implantation potential [35].

However, the definition of repeated failures requires the presence of 2 good quality embryos for transfer, a finding which cannot be available in a respectable number of patients with repeated failures. The definition of repeated failure as 3 unsuccessful ICSI cycles with good quality embryo transfer remains inapplicable because those patients suffer from having incompetent oocytes with the formation of low-quality embryos; with the prohibition of Islamic Shari "a law the substitution with donor oocytes and donor embryos. The definition of repeated failures requires modification in the future studies to cover failures due to oocytes and embryos dysmorphology. Bashiri, et al. in their review suggested that these cases should be investigated to determine the most likely etiologies of the condition, and treatment approaches should be directed towards the individual patient cases [36].

\section{Conclusion}

Repeated pregnancy failures in ICSI cycles are due to multiple morphological abnormalities of MII oocytes.

\section{Recommendation}

For those patients with repeated failures after excluding environmental and immunological factors responsible for defects in oocytes quality, genetic workup is recommended to exclude chromosomal balanced translocations.

\section{Conflict of interest}

The authors have no conflict of interest.

\section{Acknowledgement}

Thanks to all the staff members and the patients in Assisted Reproductive unit, International Islamic Center for Population Studies and Research, Al-Azhar University. 


\section{References}

1. Simon A, Laufer N (2012) Assessment and treatment of repeated implantation failure (RIF). J Assist Reprod Genet $29: 1227-1239$

2. Achache H, Revel A (2006) Endometrial receptivity markers, the journey to successful embryo implantation. Hum Reprod Updat 12: 731-746.

3. Fukui A, Funamizu A, Yokota M, Yamada K, Nakamua R, Fukuhara R, et al. (2011) Uterine and circulating natural killer cells and their roles in women with recurrent pregnancy loss, implantation failure and preeclampsia. J Reprod Immunol 90: 105-110.

4. Gonen-Gross T, Goldman-Wohl D, Huppertz B, Lankry D, Greenfield C, et al. (2010) Inhibitory NK receptor recognition of HLA-G: regulation by contact residues and by cell specific expression at the fetal-maternal interface. PLoS One 5: e8941.

5. Sanders B (20006) Uterine factors and infertility. J Reprod Med 51:169-176.

6. Azem F, Many A, Ben Ami I, Yovel I, Amit A, et al. (2004) Increased rates of thrombophilia in women with repeated IVF failures. Hum Reprod 19: 368-370.

7. Singh M, Chaudhry P, Asselin E (2011) Bridging endometrial receptivity and implantation: network of hormones, cytokines, and growth factors. J Endocrinol 210 : $5-14$

8. Elram T, Simon A, Israel S, Revel A, Shveiky D, et al. (2005) Treatment of recurrent IVF failure and human leukocyte antigen similarity by intravenous immunoglobulin. Reprod Biomed Online 11: 745-749.

9. Raziel A, Friedler S, Schachter M, Kasterstein E, Strassburger D, et al. Increased frequency of female partner chromosomal abnormalities in patients with high-order implantation failure after in vitro fertilization. Fertil Steril 78: 515-519.

10. Pehlivan T, Rubio C, Rodrigo L, Romero J, Remohi J, et al. (2003) Impact of preimplantation genetic diagnosis on IVF outcome in implantation failure patients Reprod Biomed Online 6: 232-237.

11. Yu EJ, Ahn H, Lee JM, Jee BC, Kim SH (2015) Fertilization and embryo quality of mature oocytes with specific morphological abnormalities. Clin Exp Reprod Med 42 : $156-162$.

12. Li M, Ma SY, Yang HJ, Wu KL, Zhong WX, et al. (2014) Pregnancy with oocytes characterized by narrow perivitelline space and heterogeneous zona pellucida: is intracytoplasmic sperm injection necessary? J Assist Reprod Genet 31: 285-294.

13. Rienzi L, Balaban B, Ebner T, Mandelbaum J (2012) The oocyte. Hum Reprod 27 i2-i21.

14. Balaban B, Urman B (2006) Effect of oocyte morphology on embryo development and implantation. Reprod Biomed Online 12: 608-615.

15. Baart EB, Macklon NS, Fauser BJ (2009) Ovarian stimulation and embryo quality. Reprod Biomed Online 18: 45-50.

16. Simopoulou M, Giannelou P, Bakas P, Gkoles L, Kalampokas T, et al. (2016) Making ICSI safer and more effective: A review of the human oocyte and ICSI practice. In Vivo 30: $387-400$

17. Setti AS, Figueira RC, Braga DP, Colturato SS, Iaconelli A Jr, et al. (2011) Relationship between oocyte abnormal morphology and intracytoplasmic sperm injection outcomes: A meta-analysis. Eur J Obstet Gynecol Reprod Biol 159: 364-370.

18. Orvieto R, Brengauz M, Feldman B (2015) A novel approach to normal responder patient with repeated implantation failures, a case report. Gynecol Endocrinol 31: 435-437.
19. de Cassia SFR, de Almeida Ferreira Braga DP, Semiao-Francisco L, Madaschi C, Iaconelli A Jr, et al. (2010) Metaphase II human oocyte morphology: Contributing factors and effects on fertilization potential and embryo developmental ability in ICSI cycles. Fertil Steril 94: 1115-1117.

20. Ashrafi M, Karimian L, Eftekhari-Yazdi P, Hasani F, Arabipoor A, et al. (2015) Effect of oocyte dysmorphisms on intracytoplasmic sperm injection cycle outcomes in normal ovarian responders. J Obstet Gynecol Res 41: 1912-1920.

21. Ebner T, Moser M, Tews G (2006) Is oocyte morphology prognostic of embryo developmental potential after ICSI? Reprod Biomed Online 12: 507-512.

22. Yakin K, Balaban B, Isiklar A, Urman B (2007) Oocyte dysmorphism is not associated with aneuploidy in the developing embryo. Fertil Steril 88: 811-816.

23. Loutradis D, Drakakis P, Kallianidis K, Millingos S, Dendrinos S, et al. (1999) Oocyte morphology correlates with embryo quality and pregnancy rate after intracytoplasmic sperm injection. Fertil Steril 72: 240-244.

24. Rienzi L, Ubaldi FM, Iacobelli M, Minasi MG, Romano S, et al. (2008) Significance of metaphase II human oocyte morphology on ICSI outcome. Fertil Steril 90: 1692-1700.

25. Chamayou S, Ragolia C, AlecciC, Storaci G, Maglia E, et al. (2006) Meiotic spindle presence and oocyte morphology do not predict clinical ICSI outcomes: A study of 967 transferred embryos. Reprod biomed online 13: 661-667.

26. Shi W, Xu B, Wu LM, Jin RT, Luan HB, et al. (2014) Oocytes with a dark zona pellucida demonstrate lower fertilization, implantation and clinical pregnancy rates in IVF/ICSI cycles. PLoS One 9: e89409.

27. De Sutter P, Dozortsev D, Qian C, Dhont M (1996) Oocyte morphology does not correlate with fertilization rate and embryo quality after intracytoplasmic sperm injection. Hum Reprod 11: 595-597.

28. Serhal PF, Ranieri DM, Kinis A, Marchant S, Davies M, et al. (1997) Oocyte morphology predicts outcome of intracytoplasmic sperm injection. Hum Reprod 12 $1267-1270$

29. Ten J, Mendiola J, Vioque J, de Juan J, Bernabeu R (2007) Donor oocyte dysmorphisms and their influence on fertilization and embryo quality. Reprod Biomed Online 14: 4048.

30. Sousa M, Teixeira da Silva J, Silva J, Cunha M, Viana P, et al. (2015) Embryological, clinical and ultrastructural study of human oocytes presenting indented zona pellucida. Zygote 23: 145-157.

31. De Santis L, Cino I, Rabellotti E, Calzi F, Persico P, et al. (2005) Polar body morphology and spindle imaging as predictors of oocyte quality. Reprod Biomed Online 11: 36-42.

32. Sousa M, Cunha M, Silva J, Oliveira E, Pinho MJ, et al. (2016) Ultrastructural and cytogenetic analyses of mature human oocyte dysmorphisms with respect to clinical outcomes. J Assist Reprod Genet 33: 1041-1057.

33. Macklon N (2017) Recurrent implantation failure is pathology with a specific transcriptomic signature. Fertil Steril 108: 914.

34. Vanneste E, Voet T, le Caignec C, Ampe M, Konings P, et al. (2009) Chromosome instability is common in human cleavage-stage embryos. Nat Med 15: 577-583.

35. Das M, Holzer HE (2012) Recurrent implantation failure: gamete and embryo factors. Fertil Steril 97: 1021-1027.

36. Bashiri A, Halper KI, Orvieto R (2018) Recurrent Implantation Failure-update overview on etiology, diagnosis, treatment and future directions. Reprod Biol Endocrinol 16: 121.

Copyright: $@ 2019$ Youssef HMG. This is an open-access article distributed under the terms of the Creative Commons Attribution License, which permits unrestricted use, distribution, and reproduction in any medium, provided the original author and source are credited. 